\title{
Attraction Response of Tuta absoluta Females to Solanaceous Host in Y-Tube Olfactometer
}

\author{
Abdelhady, M. A., A. A. Sarhan, M. A. M. Osman, N. S. Mandour* \\ Plant Protection Department, Faculty of Agriculture, Suez Canal University, Ismailia, Egypt
}

Received: $21 / 8 / 2020$

\begin{abstract}
Herbivore-induced plant volatiles (plant synomones) play a very crucial role in the communication of plantinsect relationships. The main objectives of the present study are to compare the attraction of solanaceous plant species, different tomato plant ages and infestation levels to tomato leaf miner (TLM) Tuta absoluta (Meyrick) (Lepidoptera; Gelechiidae) females. Results indicated that TLM females prefer tomato plants to other tested solanaceous species with attractiveness ratio of $83.3 \%$ compared to $76.6,70$ and $13.3 \%$ for potato, eggplant and pepper plants, respectively. Results also showed that the higher percentages of attraction were associated with the elder (45 days) tomato plants with an average of $76.67 \%$. The attraction response of TLM females to tomato plants inside olfactometer was higher for newly infested tomato plants (NITP) than the older previously infested plants or host-plant-complex. The attractiveness to newly TLM-infested plants was recorded at $43.33 \%$. The importance of these findings in T. absoluta management programs is discussed.
\end{abstract}

Keywords: Tuta absoluta L., Olfactormeter, host preference, response, synomones, solanaceous plants

\section{INTRODUCTION}

Plants mainly emit volatile organic compounds (VOCs) that insect herbivores exploit to recognize and efficiently locate their host plants for feeding, mating, egg-laying and aggregation of conspecifics (Metcalf and Metcalf, 1992; Jolivet, 1998; Bruce et al., 2005; Cardé and Willis, 2008; Proffit et al., 2011; Silva and Furlong, 2012). Under herbivore attack and depending upon the feeding type of the herbivore, different defense signaling pathways are activated resulting in the production of more specific volatile compounds (Walling, 2000). The induction of volatile emission is one of the most important and immediate responses of plants to herbivore attack (Mandour et al., 2011; War et al., 2011).

Plant-induced response is commonly speciesspecific according to the herbivore species, leading to a particular composition of herbivore-induced plant volatiles (HIPVs) (Stout et al., 1998; Dicke et al., 2009; Zhang et al., 2009), which are also important signals when natural enemies search for their host/prey (Dicke et al., 1990; Turlings et al., 1990, 1991; Dicke and Hilker, 2003; Mandour et al., 2011). Plant volatile compounds influence host selection of herbivorous insects. HIPVs can also affect foraging behaviors of either conspecifics or heterospecifics. Thus, the olfactory response to such plant volatile compounds is a key component for the adaptation and persistence of insect pests, especially invasive alien species.

Invasive species represent a potential threat to agroecosystems of the invaded area (Olson, 2006; Haack et al., 2010; Ragsdale et al., 2011). The invasive tomato leafminer (TLM), Tuta absoluta (Meyrick) (Lepidoptera: Gelechiidae), is one of such species. Since its detection in Egypt at the end of 2009, TLM has become a serious threat to most greenhouse and open-field tomato production areas (Mohammed, 2010; Caparros Megido et al., 2012). TLM might cause major crop yield and economic losses in tomatoes of up to $80-100 \%$ if the pest is not managed properly (EPPO 2005; Picanco et al., 2007; Desneux et al., 2010). T. absoluta is an oligophagous insect (Siqueira et al., 2001). The main host of $T$. absoluta is tomato (Solanum lycopersicum L.; Solanaceae); however, other cultivated host plants, principally solanaceous species, may also be attacked. Unfortunately, there are few reports on the trophic relationship between $T$. absoluta and its potential host-plants. Host plant choice is important for the development of TLM with subsequently differences in the insect life history. The understanding of the host-plant range and the patterns of crop utilization, could allow predicting the possible expansion to other crops, resulting of great importance in the integrated pest management (Hill et al., 2004).

Therefore, this research aimed to study the attraction response and host preference of TLM females to different solanaceous plants as well as the influence of plant age and infestation status of tomato plants on the olfactory response of TLM using a Y-tube olfactrometer.

\section{MATERIALS AND METHODS}

\section{Rearing of T. absoluta}

Laboratory culture of $T$. absoluta was initially setup from the infested tomato plants collected from tomato fields around Ismailia city, Egypt. The infested leaves or fruits were kept in rearing cages $(40 \mathrm{~cm}$ in width $\times 60 \mathrm{~cm}$ in length $\times 80 \mathrm{~cm}$ in height), and provided with fresh tomato plants to complete the development of TLM immature stages. Newly formed pupae were collected regularly and kept in $12 \mathrm{~cm}$ Petri dish until emergence. Emerged adults were collected by an aspirator and confined in an ovipositional cage (40 cm in width $\times 60 \mathrm{~cm}$ in length $\times 80 \mathrm{~cm}$ in height), which include a cotton piece moistened with $10 \%$ honey solution for moth feeding and intact tomato plants (20-30 cm height) for egg laying. Tomato plants harboring eggs of TLM were transferred daily to rearing cage and replaced by another fresh batch of tomato plants and so on until the death of all TLM adults. Rearing cages were kept at room temperature of $25 \pm 2^{\circ} \mathrm{C}$ and $60 \pm 10 \%$ R.H. 


\section{Y-tube olfactometer}

A modified Y-tube olfactometer resembles to that of Y-tube classic style described earlier by Holtmann (1963), Sabelis and van de Baan (1983) was used. The modified Y-tube olfactometer was prepared entirely from approved glass and plastic materials fittings for easy disassembly for cleaning. The Y-tube device was designed with several accessories of inline odor source chamber with $1 / 4$ " tube quick disconnect in the removable head (OSI), $1 / 4$ " tube adaptor for use with direct air and large odor source chambers (OSE), specimen adaptor for inserting test subjects and air exit port (SA), and joint clips for securing an inner ground joint (Adaptors) to an outer ground joint (Y-Tube Body).All adaptors were locked in place with joint clips.

The device pathway based on the air flows from its source (air pump) to an active charcoal flask to purify the air from any carrying odors. Air flow can also be measured by an air flowmeter to control the amount of air entering the odor source flask. Each odor source flask was connected to one arm of the dual choice olfactometer and the two arms were united in one arm ended with the insect release point.

\section{Experiments}

\section{Olfactometer bioassay on TLM}

Series of experiments were conducted using the dual choice (Y-tube) olfactometer to evaluate the attraction response of $T$. absoluta adults to different treatments. The tested treatments were four solanaceous plant species (tomato, potato, eggplant and pepper), four tomato ages 8 days, 15 days, 30 days and 45 days) and four status of infestations i.e. 1) intact plants (fresh and un-infested plants), 2) newly infested tomato plants (NITP) (infested plants with TLM eggs and neonates), 3) previously infested tomato plants (PITP) (infested plants washed by water after removing all TLM stages and its by-products) and 4) host-plantcomplex (HPC) (infested plants with TLM immatures and its by-products such as feces and exuviae). Odor source were initially tested separately with blank in the two arms of Y-tube olfactometer, and then each host plant treatment was tested with each other to evaluate the preference in attractiveness of TLM females. In all experiments, newly emerged T. absoluta females (6 hours) were taken away from rearing cage directly after emergence using an aspirator and released into the releasing point inside the olfactometer. Depending on the attractiveness of the tested odor sources, females were moved to choose one direction of the two arms inside the olfactometer. Tested $T$. absoluta females were given 5 minutes to determine their choice, and females that didn't enter any arm after that time were removed from the tube and considered as no choice.
Thirty females of T. absoluta were tested in each treatment for either solanaceous plant species or tested tomato plants age. The thirty replicates were performed in three successive days with ten individuals each time. Each female was used only once then discarded. Plants used as odor sources were replaced by another non tested one every 5 replicates. The odor sources were also relocated every 5 replicates in the Y-tube arms to avoid the impact of source position. Due to the nocturnal activity of the adults, all experiments were carried out between 8:00 P.M. and 2:00 A.M. The choice of adults and the time taken were recorded in each treatment.

\section{Statistical analysis:}

All data were analyzed using t-test on one-way ANOVA (SPSS Statistics). Probability levels lower than 0.05 were held to be significant.

\section{RESULTS}

Response of $T$. absoluta to solanaceous species in olfactometer

\section{Solanaceae species versus blank}

Tomato was the most attractive test plant to TLM females with an average of $83.33 \%$ compared to $6.67 \%$ for the blank, while $6.67 \%$ of adults had no choice. Potato plants came in the second rank after tomato in its attractiveness to TLM females with an average of $76.67 \%$. The attraction response for eggplant and pepper plants was 70 and $13.33 \%$, respectively (Fig 1).

\section{Host preference within solanaceous plants}

The attraction response of TLM adults to tomato plants was higher than that of eggplant at $53.33 \%$ and $30 \%$, respectively. Attraction to tomato plants was also higher at 56.7 compared to $16.7 \%$ in potato plants. As for tomato vs. pepper plants, the percentages of attraction were 73.33 and $13.33 \%$, respectively (Fig 2).

\section{Response of $T$. absoluta to different tomato plant ages}

\section{Tomato age versus blank}

As shown in (Fig 3), there is a direct relationship between the attraction response of TLM females and the age of tomato plants. The higher percentages of attraction were always associated with the 30 and 45-day-old-tomato-plants with attraction averages of 83.33 and $83.33 \%$, respectively. Data further proved that the respective percentages of the attraction response of TLM adults to 8 and 15-day-oldplants were the lowest at 50 and $63.33 \%$, respectively. There were significant differences in terms of percentage of attraction among all tested tomato ages $(\mathrm{F}=3.333 ; P=0.402)$. 

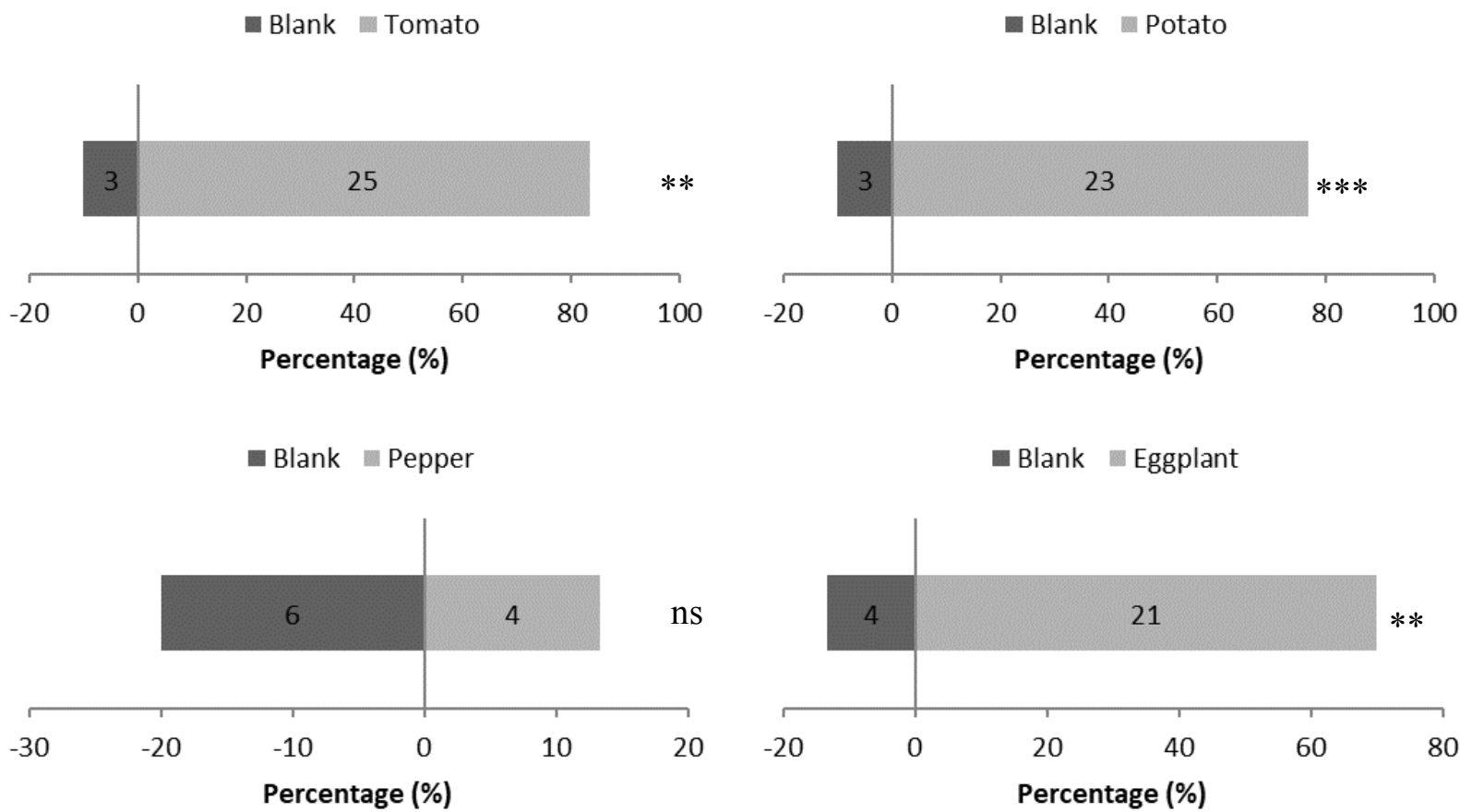

Fig (1): Response of TLM females to four solanaceous plants in Y-tube olfactrometer bioassay

- ns indicates no significant differences

- Bars with astricks $(*)$ indicates significant differences

- Numbers over the bars indicate number of responsive individuals
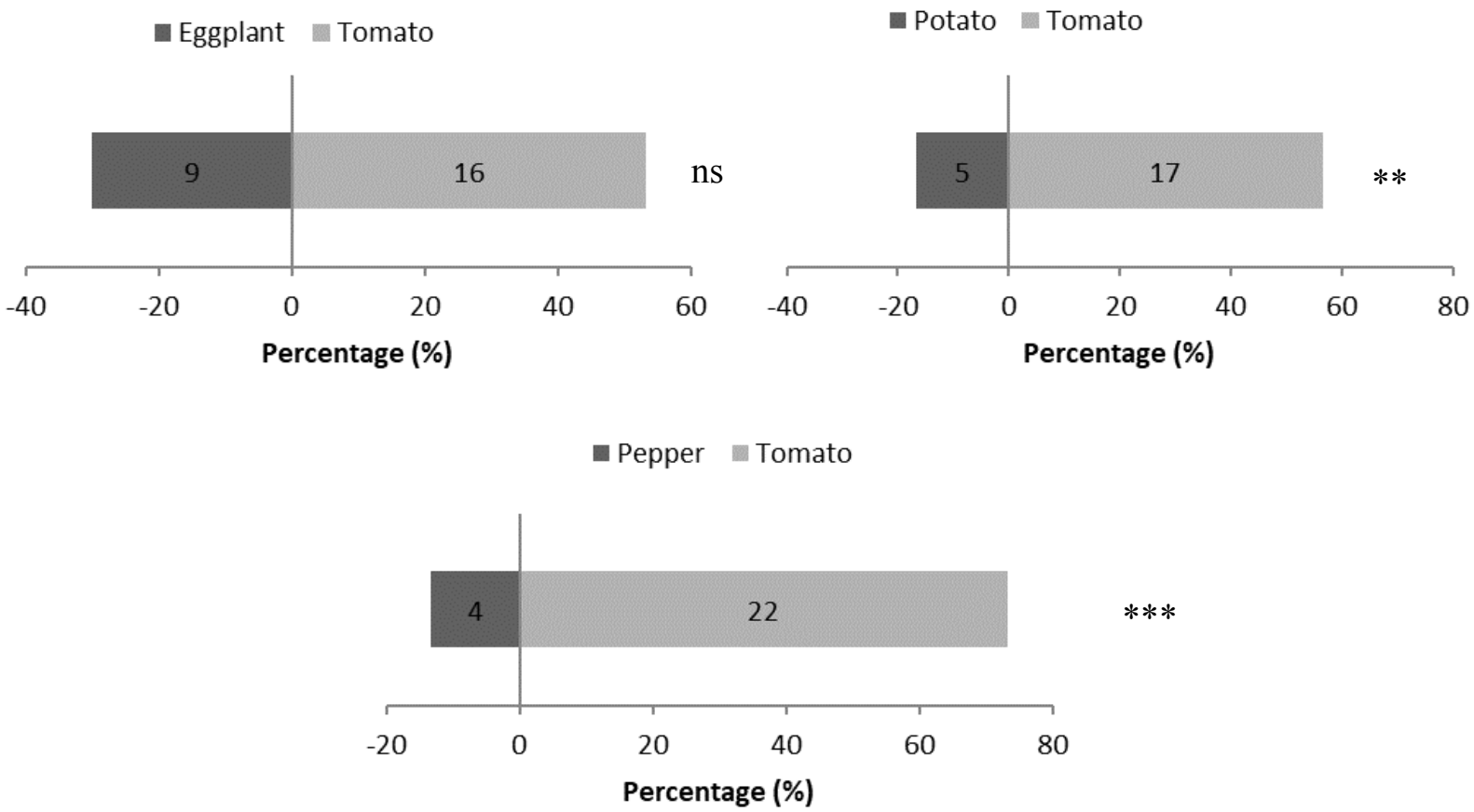

Fig (2): Response of TLM females to tomato plants versus eggplant, potato and pepper in Y-tube olfactrometer bioassay - ns indicates no significant differences

- Bars with astricks $(*)$ indicates significant differences

- Numbers over the bars indicate number of responsive individuals 

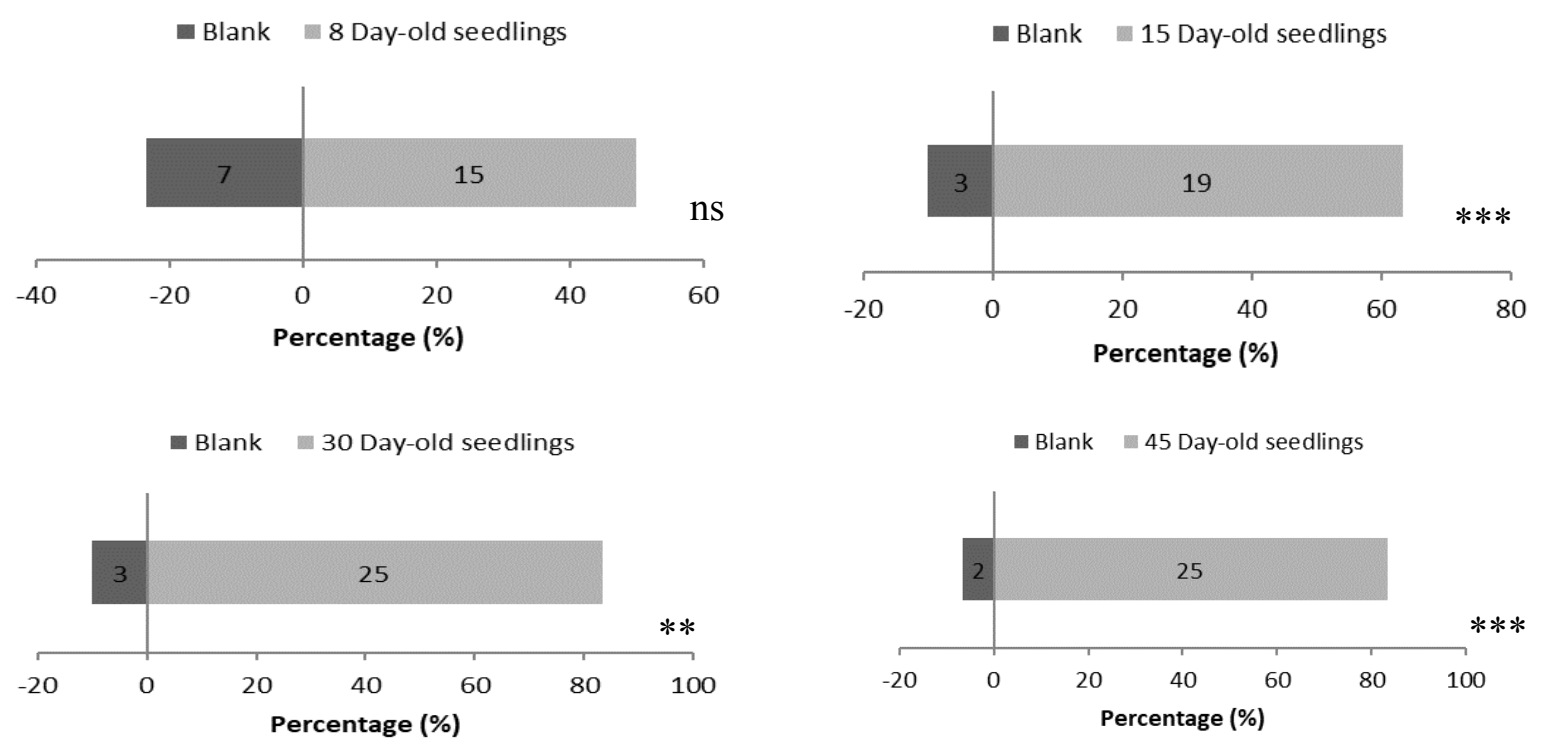

Fig (3): Response of TLM females to tomato plants at different ages in Y-tube olfactrometer bioassay - ns indicates no significant differences

- Bars with astricks $(*)$ indicates significant differences

- Numbers over the bars indicate number of responsive individuals

\section{Host preference within tomato ages}

The highest percentages of TLM response were always associated with the elder tomato plants. The highest percentage of attraction was $76.67 \%$ when 45 day-old tomato plants were tested versus 8-day-old
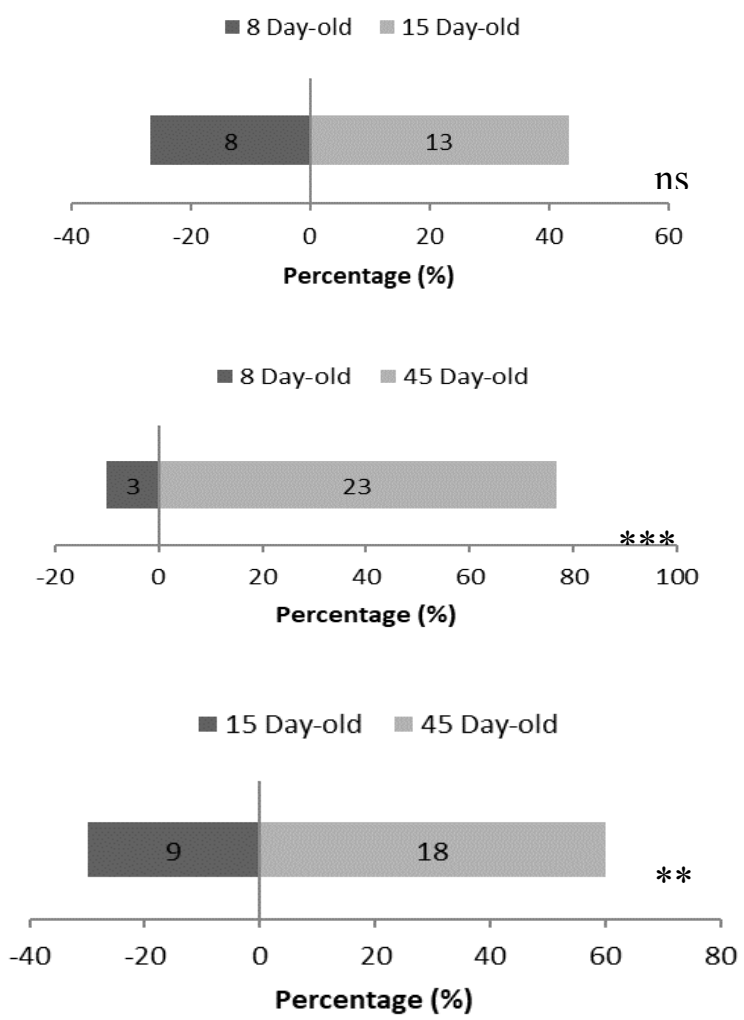

plants $(10 \%)$. Data also proved that the respective percentages of the attraction response of TLM adults to 8 Day-old seedlings versus 15-day-old, 30-day-old and 45-day-old plants were 26.67, 23.33 and $10 \%$, respectively (Fig 4).
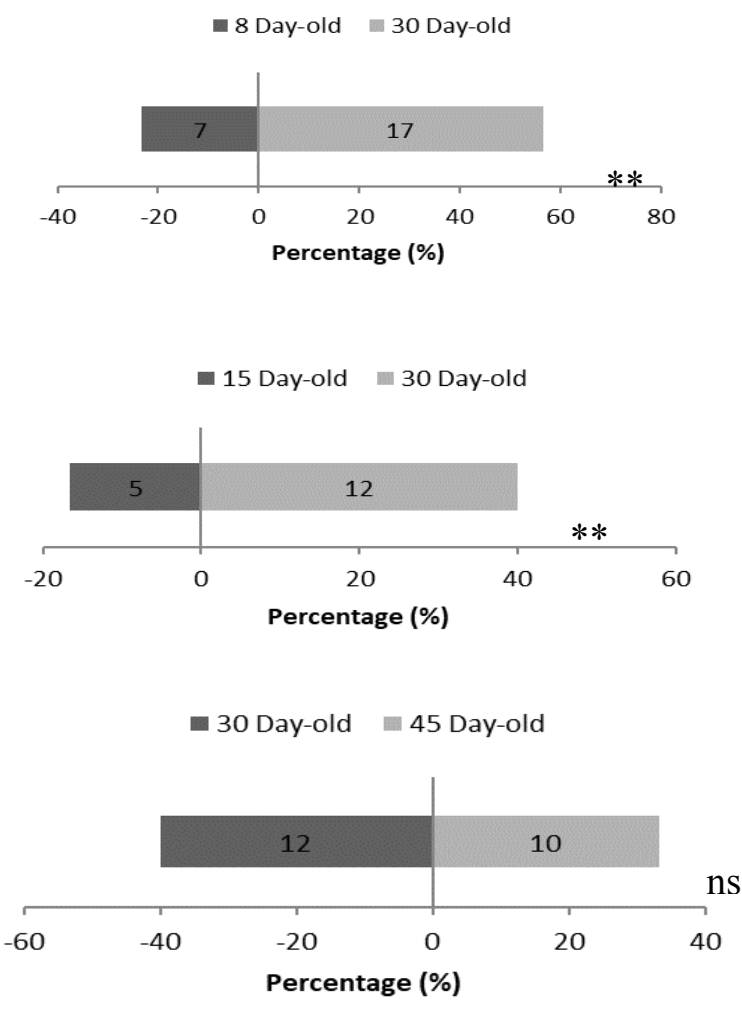

Fig (4): Response of TLM females in dual choice of tomato seedlings at different ages in Y-tube olfactrometer bioassay - ns indicates no significant difference

- Bars with astricks $(*)$ indicates significant differences

- Numbers over the bars indicate number of responsive individuals 


\section{Response of females to TLM-infested plants Intact versus infested}

As presented in Fig (5), the un-infested TLM females prefer tomato plants to ensure their offspring. The attraction response of TLM adults to the intact plants was $83.33 \%$ compared to $10 \%$ for the blank and $6.67 \%$ of the tested TLM females had no choice. Also the attractiveness percentages to the infested tomato plants were $30 \%$ compared to $23.33 \%$ and $46.67 \%$ for blank and no choice response, respectively (Fig 5).

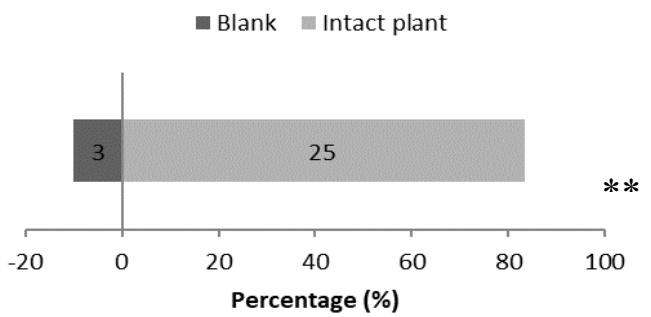

TLM adults preferred intact plants for laying their eggs compared to the infested tomato plants with the attraction response of $70 \%$ and $16.67 \%$ for the intact and infested tomato plants, respectively.

Results further indicated that the tested treatments showed significant differences in the attraction response of TLM adults i.e., $(\mathrm{F}=0.055 ; P=$ $0.816)$ for intact plants vs. blank, $(\mathrm{F}=0.178 ; P=0.680)$ for infested plants $v s$. blank and $(\mathrm{F}=3.134 ; P=0.089)$ for intact plants $v s$. infested plants.

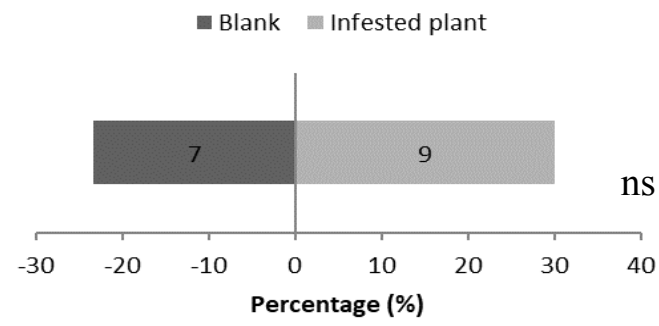

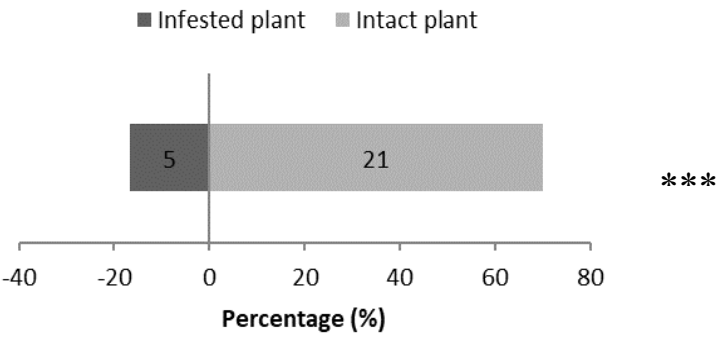

Fig (5): Effect of tomato infestation on the attraction response of TLM females in olfactrometer bioassay - ns indicates no significant differences

- Bars with astricks $(*)$ indicates significant differences

- Numbers over the bars indicate number of responsive individuals

\section{Host preference within tomato infestation status}

The attraction response of TLM females to tomato plants inside olfactometer was higher for newly infested tomato plants than the older infested ones. The

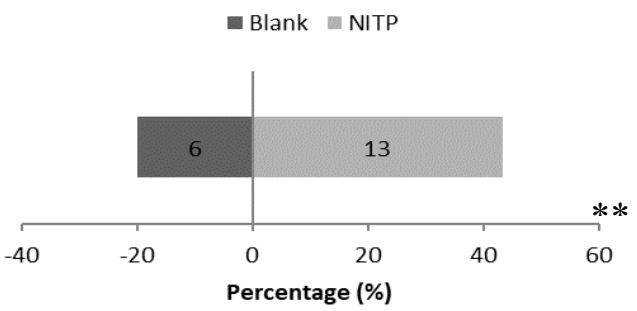

attractiveness to newly infested-plants was recorded at $43.33 \%$ compared to $20 \%$ in blank arm. The TLM attraction was $53.33 \%$ for previously infested tomato plants (PITP) versus 16.67\% in blank (Fig 6).

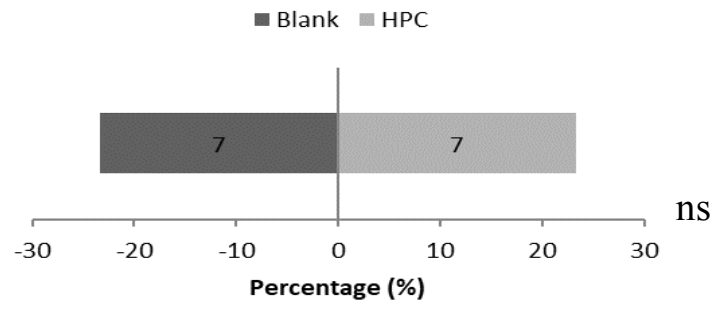

Fig (6): Attraction response of TLM females to different status of tomato infestation in Y-tube olfactrometer bioassay NITP $=$ Newly Infested Tomato Plant, PITP= Previously Infested Tomato Plant, HPC $=$ Host Plant Complex

- ns indicates no significant differences

- Bars with astricks $(*)$ indicates significant differences

- Numbers over the bars indicate number of responsive individuals 

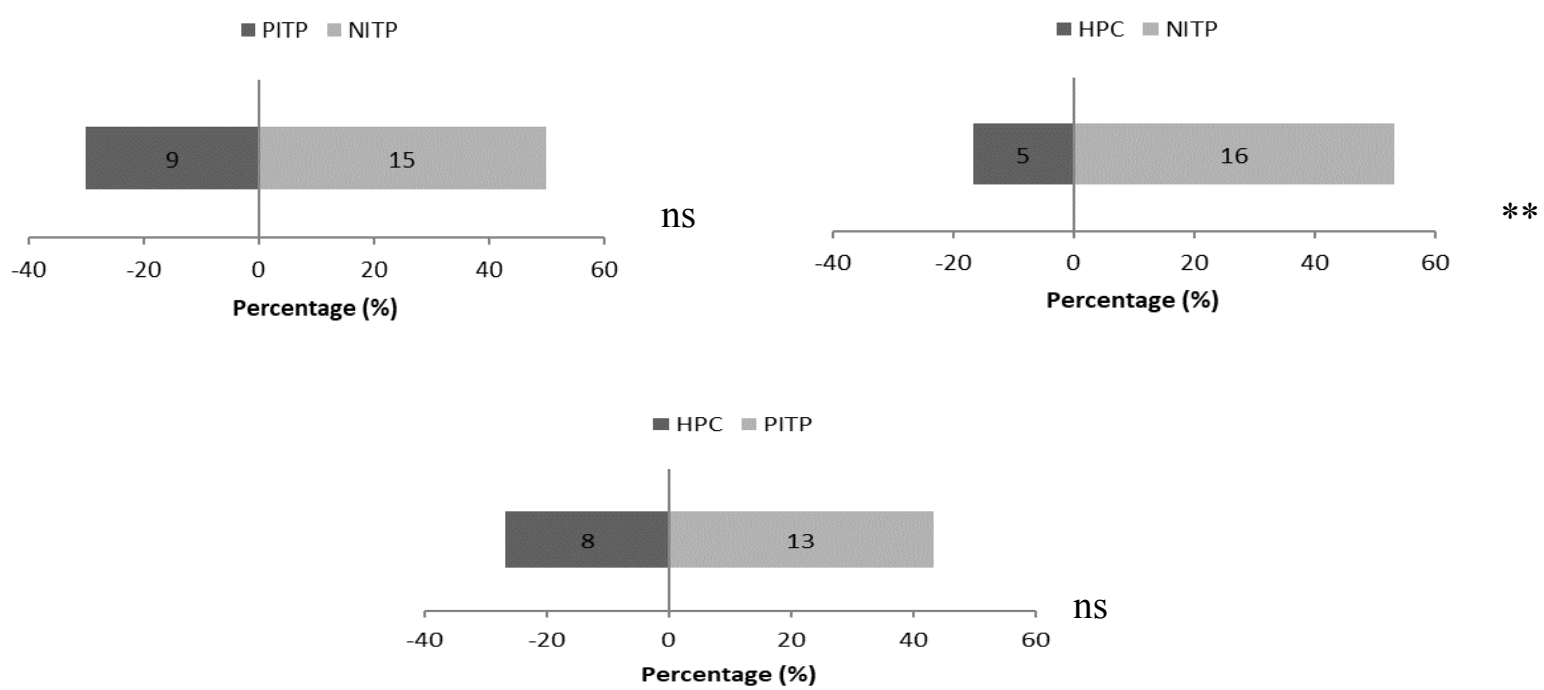

Fig (7): Attraction response of TLM females to different status of infestation of tomato plants as dual choice in Y-tube olfactrometer bioassay

$\mathrm{NITP}=$ Newly Infested Tomato Plant, PITP= Previously Infested Tomato Plant, HPC= Host Plant Complex

- ns indicates no significant differences

- Bars with astricks $(*)$ indicates significant differences

- Numbers over the bars indicate number of responsive individuals

\section{DISCUSSION}

Insect species must find certain host plant species to insure food, complete their development and maintain their survival and offspring. Plant volatiles are detected by highly sensitive olfactory receptor neurons (Bruce and Pickett, 2011). Odors from host plants play a vital role in the attraction of insect herbivores (Guerin and Visser, 1980), allowing herbivores locating a host plant from a distance (Bernays and Chapman, 1994). Volatile phytochemicals can serve as airborne semiochemicals that mediate plant-insect interactions (Beyaert and Hilker, 2014; Meiners, 2015), promoting or deterring herbivore females to locate their oviposition sites (Bruce et al., 2005; Bruce and Pickett, 2011; Bawin et al., 2014; Biasazin et al., 2014; Schäpers et al., 2015; Scheidler et al., 2015).

In the present study using the dual choice (Ytube) olfactometer, results revealed that the attraction response of TLM females to plant odor was host-plantdependent. Pepper plants were not attractive to $T$. absoluta, unlike the other three solanaceous species of tomato, potato and eggplant. This can be explained by the fact that pepper plants may be actively avoided by females due to the presence of constituents that deter or prevent $T$. absoluta females from attracting to it. Results of Y-tube olfactometer confirmed the refrain of TLM females to lay eggs on pepper (unpublished data).

Findings in this study regarding behavioral response of TLM on solanaceous plants are scientifically explained by results observed in olfactometer assay. Here, tomato was the most preferred plant by $T$. absoluta females, followed by potato and eggplant in olfactometer assay. These variations in the attractiveness response among the tested solanaceous plant species may be due to the ability of plants to produce plant volatiles with different compositions and quantities. These differences might explain the host searching behavior response exhibited by $T$. absoluta females during the behavioral assays. As T. absoluta females were more attracted to tomato plants compared to potato and eggplant plants. Such results were expected because tomato is considered to be the ideal host for T. absoluta development (Pereyra and Sanchez, 2006; Miranda et al., 1998). These findings were in harmony with those obtained by Megido et al. (2014) who found that the host finding behavior of T. absoluta is mediated by solanaceous volatiles, and preferences might be explained by the high release of terpenes by plants. The results also partially support earlier studies (e.g. Reisenman et al., 2013; Jansen et al., 2009; Fraser et al., 2003).

Age of tomato plants yielded different attraction responses of TLM in olfactometer assay. TLM response increased as tomato plants aged from 15 to 45 days. These results were expected as the composition of the volatiles emissions within a plant can largely differ among organs and may vary with the circadian rhythm, plant age and phenological state (Hare, 2010). In this regards, earlier studies proved that the volatile organic compounds emission rates may vary from leaf to leaf, plant to plant, season, age, and between community level, genotypes (Dicke, 1999; Paré and Tumlinson, 1999; Holopainen and Gershenzon, 2010; Niinemets et al., 2010; Grote et al., 2013; Alves et al., 2014), the environmental conditions where the plant grows, as well as the number of herbivore species attacking it (Horas et al., 2014) and time after last herbivory (Mandour et al., 2011).

Also, TLM adults always prefer the non-infested tomato plants to ensure their offspring. The attraction response to tomato intact plants was higher than the attraction to the infested ones with an average of 
$83.33 \%$ compared to $70 \%$ in infested plants. Thus, TLM females discriminate the infested tomato plants from uninfested plants (Proffit et al., 2011; De Backer et al., 2014). This can be explained that TLM females are exposed to a variety of cues, including plant volatiles, contact chemicals, and visual signals, which help to determine the suitability of a host plant (Awmack and Leather, 2002). Proffit et al., (2011) found that the attraction and oviposition of female $T$. absoluta are mediated by the volatile signature of their host plant. Bawin et al. (2014) reported that oviposition behavior of TLM is dependent on the infestation status of host plant by conspecifics. They suggested that the preferences between conspecific-infested and noninfested host seems to be controlled by a more complex mechanism than a simple intra-specific competition model, and other factors as insect parasitoids may have play a crucial role in foraging the leafminer oviposition behavior. They concluded that these results might provide useful information and perspectives for the development of further pest control strategies.

\section{CONCLUSION}

Clearly, plant species, plant age and infestation incidence are important factors that effectively influence the attraction response of TLM females. The attraction response of TLM adults to tomato plants was higher than the other three tested solanaceous species. Obviously, there was a direct relationship between the attraction response of TLM adults and the age of tomato plants and the higher percentages of attraction were always associated with the 30 and 45-day-old-tomatoplants. Finally, TLM females prefer non-infested solanaceous plants to infested ones for its offspring survival

\section{REFERENCES}

Alves, E., P. Harley, F. De, C. Gonçalves, C. Moura and K. Jardine (2014). Effects of light and temperature on isoprene emission at different leaf developmental stages of Eschweilera coriacea in central Amazon. Acta Amazonica, 44(1): 9-18.

Awmack, C. and S. Leather (2002). Host plant quality and fecundity in herbivorous insects. Annual review of entomology, 47(1): 817-844.

Bawin, T., L. Backer, D. Dujeu, P. Legrand, R. Caparros Megido, F. Francis and F. Verheggen (2014). Infestation level influences oviposition site selection in the tomato leaf miner Tuta absoluta (Lepidoptera: Gelechiidae). Insects, 5(4): 877-884.

Bernays E. A. and R. F. Chapman (1994). Host-plant selection by phytophagous insects. Chapman and Hall, New York, 230-287.

Beyaert, I. and M. Hilker (2014). Plant odour plumes as mediators of plant-insect interactions. Biological reviews of the Cambridge Philosophical Society, 89(1): 68-81.

Biasazin, T., M. Karlsson, Y. Hillbur, E. Seyoum and T. Dekker (2014). Identification of host blends that attract the African invasive fruit fly, Bactrocera invadens. Journal of Chemical Ecology, 40(9): 966-976.

Bruce, T. and J. Pickett (2011). Perception of plant volatile blends by herbivorous insects Finding the right mix. Phytochemistry, 72(13): 1605-1611.

Bruce, T., L. Wadhams and C. Woodcock (2005). Insect host location: A volatile situation. Trends in Plant Science, 10(6): 269-274.

CoHort Software (2005). Costat Statistical package (version 6.311), P.O.Box 1149, Berkeley, CA, 94701, USA.

De Backer, L., R. Caparros Megido, E. Haubruge and F. Verheggen (2014). Macrolophus pygmaeus (Rambur) as an efficient predator of the tomato leaf miner Tuta absoluta (Meyrick) in Europe. Biotechnology, Agronomy, Society, Environment, 18:536-543.

Desneux, N., E. Wajnberg, K. Wyckhuys, G. Burgio, S. Arpaia, C. Narváez-Vasquez, J. GonzalezCabrera, D. Ruescas, E. Tabone, J. Frandon, J. Pizzol, C. Poncet, T. Cabello and A. Urbaneja (2010). Biological invasion of European tomato crops by Tuta absoluta: Ecology, geographic expansion and prospects for biological control. Journal of Pest Science, 83: 197-215.

Dicke, M. (1999). Are herbivore-induced plant volatiles reliable indicators of herbivore identity to foraging carnivorous arthropods? Entomologia Experimentalis et Applicata, 91: 131-142.

EPPO (2005). European and Mediterranean Plant Protection Organization (EPPO), 35(3): 434435.

Fraser, A. M., W. L. Mechaber and J. H. Hildebr (2003). Electroantennographic and behavioral responses of the sphinx moth Manduca sexta to host plant headspace volatiles. Journal of Chemical Ecology, 29: 1813-1833.

Grote, R., R. K. Monson and Ü Niinemets (2013). Leaflevel models of constitutive and stress-driven volatile organic compound emissions. Biology, controls and models of tree volatile organic compound emissions. Springer; Berlin, 5: 315-355.

Guerin, P. M. and J. H. Visser (1980). Electroantennogram responses of the carrot fly Psila rosae, to volatile plant components. Physiological Entomology, 5: 111-119.

Hare, J. (2010). Ontogeny and season constrain the production of herbivore $\square$ inducible plant volatiles in the field. Journal of Chemical Ecology, 36: 1-12.

Holopainen, J. K. and J. Gershenzon (2010). Multiple stress factors and the emission of plant VOCs. Trends in Plant Science, 15: 176-184.

Holtmann, H. (1963). Untersuchungenzurbiologie der getreide-Thysanopteren.Teil II. Zeitschriftfurangewandte Entomologie, 51: 285-299. 
Horas, V. R., M. A. Silva, V. Annies, B. H. Maia, F. A. Marques and M. F. Silva (2014). Noctuidaeinduced plant volatiles: current situation and prospects. Química Nova, 37(10), 1663-1669.

Jansen, R. M. C., M. Miebach, E. Kleist, E. J. van Henten and J. Wildt (2009). Release of lipoxygenase products and monoterpenes by tomato plants as an indicator of Botrytis cinerea-induced stress. Plant Biology, 11: 859-868.

Mandour, N. S., Y. Kainoh and R. Ozawa (2011). Effects of time after last herbivory on the attraction of corn plants infested with common arym worms to a parasitic wasp Cotesia kariyai. Journal of Chemical Ecology, 37: 267-272.

Megido R. C., L. De Backer, R. Ettaïb, Y. Brostaux, M. L. Fauconnier, P. Delaplace, G. Lognay, M. S. Belkadhi, E. Haubruge, F. Francis and F. J. Verheggen (2014). Role of larval host plant experience and solanaceous plant volatile emissions in Tuta absoluta (Lepidoptera: Gelechiidae) host finding behavior. Arthropod-Plant Interact, 8:293-304.

Meiners, T. (2015). Chemical ecology and evolution of plant-insect interactions: A multi trophic perspective. Current Opinion in Insect Science, 8: 22-28.

Miranda, M., M. Picanço, J. Zanuncio and R. Guedes (1998). Ecological Life Table of Tuta absoluta (Meyrick) (Lepidoptera: Gelechiidae). Biocontrol Science and Technology, 8: 597-606.

Niinemets, Ü., A. Arneth, U. Kuhn, R. K. Monson, J. Peñuelas and M. Staudt (2010). The emission factor of volatile isoprenoids: stress, acclimation, and developmental responses. Biogeosciences 7: 2203-2223.

Paré, P. and J. Tumlinson (1999). Plant Volatiles as a Defense against Insect Herbivores. Plant physiology, 121(2): 325-332.

Pereyra, P. C. and N. E. Sánchez (2006). Effect of two solanaceous plants on developmental and population parameters of the tomato leaf miner, Tuta absoluta (Meyrick) (Lepidoptera: Gelechiidae). Neotropical Entomology, 35(5): 671-676.
Proffit, M., G. Birgesson, M. Bengtsson, R. Reisjr, P. Witzgall and E. Lima (2011). Attraction and oviposition of Tuta absoluta females in response to tomato leaf volatiles. Journal of Chemical Ecology, 37(6): 565-574.

Reisenman, C. E., J. A. Riffell, K. Duffy, A. Pesque, D. Mikles and B. Goodwin (2013). Speciesspecific effects of herbivory on the oviposition behavior of the moth Manduca sexta. Journal of Chemical Ecology, 39: 7689.

Ruberson, J. R. and P. G. Tillman (1999). Effect of selected insecticides on natural enemies in cotton: laboratory studies. Proceedings Beltwide Cotton Conferences, 2: 1210-1213.

Sabelis, M. W. and H. E. Van de Baan (1983). Location of distant spider-mite colonies by phytoseiid predators: demonstration of specific kairomones emitted by Tetranychus urticae and Panonychus ulmi (Acari: Tetranychidae). Entomologia Experimentalis et Applicata, 33: 303-314.

Schäpers, A., S. Nylin, M. A. Carlsson and N. Janz (2015). Specialist and generalist oviposition strategies in butterflies: maternal care or precocious young. Oecologia, 180: 335-343.

Scheidler, N., C. Liu, K. Hamby, F. Zalom and Z. Syed (2015). Volatile codes: Correlation of olfactory signals and reception in Drosophila-yeast chemical communication. Scientific reports, 5:1-13.

Siqueira, H. A., R. N. Guedes and M. C. Picanço (2001). Insecticide resistance in populations of Tuta absoluta (Lepidoptera: Gelechiidae). Agricultural and Forest Entomology, 2(2): 147-153.

Steel, R. D. and J. H. Torrie (1980). Principles and procedures of statistics. A biometrical approach, $2^{\text {nd }}$ Edition, McGraw-Hill Book Company, New York.

Walling, L. L. (2000). The myriad plant responses to herbivores. Journal of Plant Growth Regulation, 19(2): 195-216.

War, A. R., M. G. Paulraj, M. Y. War and S. Ignacimuthu (2011). Role of salicylic acid in induction of plant defense system in chickpea (Cicera rietinum L.). Plant Signaling \& Behavior, 6(11): 1787-1792.

\footnotetext{
إستجابة إنجذاب إناث حفار أوراق الطماطم إلى عوائل نباتات الباذنجانية داخل جهاز مقياس الثم

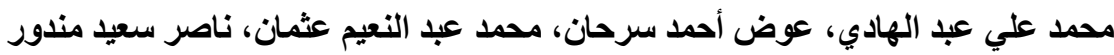

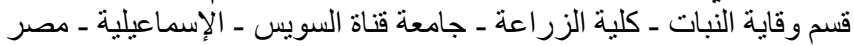

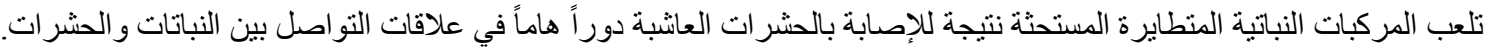

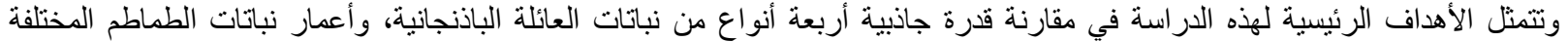

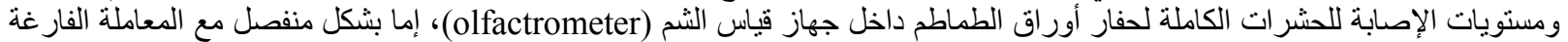

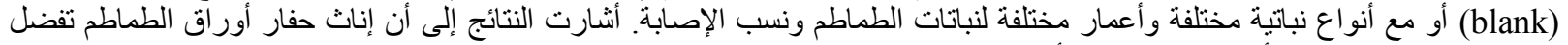

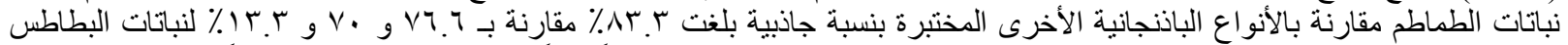

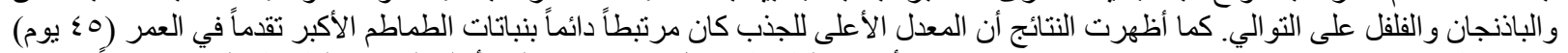

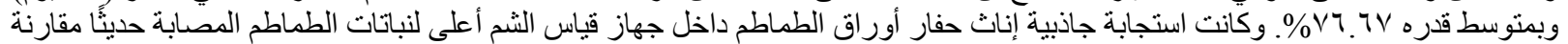

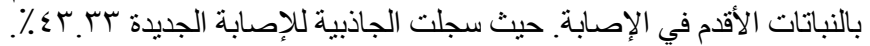

